\title{
CHILE EN LAS CALLES DERRUMBANDO LOS MUROS DEL NEOLIBERALISMO ${ }^{1}$
}

\section{CHILE IN THE STREETS BRINGING DOWN THE WALLS OF}

\author{
NEOLIBERALISM
}

\author{
Pablo Monje-Reyes ${ }^{2}$ \\ Dedicado a mis hijos Emilio y Luciano, \\ por un futuro digno.
}

\section{PRESENTACIÓN}

El objetivo de este ensayo es describir y analizar lo que ha sido el "estallido social" en Chile a partir del 18 de octubre de 2019. La construcción analítica de este trabajo se organiza a partir de diversas columnas que fueron desarrollando a partir de cómo iba avanzando movilización, no solo como un hecho histórico inédito en los últimos 40 años de la historia de Chile, sino también observando, como los actores políticos y sociales han ido actuando en su condición de clase y como esta condición los vincula a su posición política e histórica del momento que estamos viviendo. Como planteara Marx

[...] los hombres moldean su propia historia, pero no la hacen libremente, influidos por condiciones que ellos han elegido, sino bajo las circunstancias con que se tropiezan inexorablemente, que están ahí, transmitidas por el pasado. La herencia de todas las generaciones muertas acosa las mentes de los vivos como una pesadilla. Y cuando se disponen a sublevarse y sublevar el estado de las cosas, a crear algo inusitado, en estos tiempos de crisis y rebelión es precisamente cuando, con miedo, conjuran en su auxilio los espíritus de antaño, se disfrazan con sus nombres, sus consignas de guerra, sus vestimentas, para interpretar una nueva escena de la historia universal con ese traje de vejez respetable y esas palabras prestadas" (MARX, 1998 ed.,p.17).

\footnotetext{
${ }^{1}$ Agradezco las opiniones de los compañeros Juan Patricio Ponce y Oscar Azocar que, con sus visiones críticas a los textos originales, mejoraron el análisis y presentación de ideas.

${ }^{2}$ Atualmente é Professor de la Universidad de Chile y Asesor de la Municipalidad de Recoleta - Chile. Lic. en Ciencias Políticas, U. de Los Lagos; Magister en Gestión y Políticas Públicas, DII, U. de Chile. e-mail: pamore7@gmail.com
} 


\section{novistet

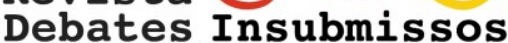

Desde la perspectiva metodológica este ensayo parte de la siguiente premisa

[...] actualmente la sociedad capitalista se encuentra en un periodo de crisis planetaria, pero pocos pueden creer que sea probable, o siquiera posible, que como resultado de esta crisis se produzca el advenimiento del socialismo en algún país. Así pues, ¿en qué podemos basar nuestras esperanzas, si no es una ciega voluntad o en un acto de fe inevitabilidad histórica? Pero los marxistas nunca han sido ciegos voluntaristas, ni tampoco se han basado en la inevitabilidad histórica o la generalización filosófica en abstracto. Siempre han tratado de identificar las fuerzas sociales y políticas específicas y las coyunturas y situaciones concretas que cavaran la tumba del capitalismo". (HOBSBAWM, 2011, p.113).

Para el análisis de las coyunturas y situaciones concretas lo defino como lo planteara

\section{Gramsci}

[...] un estudio sobre la forma en que es preciso analizar las "situaciones", o sea la forma en que es preciso establecer los diversos grados de las relaciones de fuerzas, puede prestarse a una exposición elemental de ciencia y arte político, entendida como un conjunto de cánones prácticos de investigación y de observaciones particulares, útiles para subrayar el interés de por la realidad efectiva (GRAMSCI, 1972, p.80) por tanto, hay que observar las condiciones de las acciones políticas en su relación de fuerza en diversos momento y grados a saber; a) la relación de fuerza sociales estrechamente ligadas a la estructura, objetiva, independiente de la voluntad de los hombres, que puede ser medida con sistemas de las ciencias exactas o físicas; b) el momento de la relación de las fuerzas políticas; es decir, la valoración del grado de homogeneidad, autoconciencia y organización alcanzado por los diferentes grupos sociales. Este momento, a su vez puede ser analizado y dividido en diferentes grados que corresponda a los diferentes momentos de la conciencia política, tal como se manifestaron hasta ahora en la historia; y c) el tercer momento es el de la relación de las fuerzas militares, inmediatamente decisivo según las circunstancia (GRAMSCI, 1972,; p. 88 -92).

El tercer punto quedará pendiente en el análisis porque están transcurriendo hechos

políticos y legislativos que darían las condiciones para el actuar de las fuerzas armadas en las próximas semanas en Chile.

El transcurrir del texto de este trabajo se plantea una crisis del modelo neoliberal de dominación practicado en los últimos 40 años en Chile. Se entenderá esta crisis como la plateara Gramsci

[...] ocurre porque la clase dirigente fracasó en alguna gran empresa para lo cual demandó o impuso por la fuerza el consenso de las grandes masas (...) o porque vastas masas (...) pasaron del golpe de la pasividad política a una cierta actividad y plantearon reivindicaciones que en su inorgánico conjunto constituyen una revolución. Se habla de "crisis de autoridad" y esto es precisamente la crisis de hegemonía o crisis del estado en su conjunto" (GRAMSCI, 1972, p. 98 -99).

Por último, este ensayo no termina en el cumulo de síntesis y conclusiones en cada uno de los apartados, este trabajo solo grafica el momento político que está viviendo y que se va seguir 
viviendo en los próximos meses. Quizás el desafío sea continuar post publicación mejorando el análisis y dando pistas de cómo seguir un avance al cambio de forma de estado y de hacer política en Chile.

\section{COMIENZAN LAS PROTESTAS EN CHILE 18 OCTUBRE}

Ha pasado mucha agua bajo los puentes de la historia desde aquel virtuoso día 18 de octubre, en que nuestra preciosa y valiente juventud saltó el primer torniquete del tren metropolitano en Santiago en una inédita medida de insurrección social para decirle a todo Chile; ¡ya no más! Y así, en cada jornada posterior las protestas han corrido como reguero de pólvora por todas las calles del valle urbano del Mapocho y de las pequeñas y grandes ciudades del país. Chile comienza a respirar desde su rabia y sus sueños, desde sus decepciones y sus esperanzas, desde sus logros y sus frustraciones. Se levanta el pueblo, se alza el poder popular, el pánico invade al poder y comienza el enfrentamiento. La lucha se inicia en las alamedas, continúa en las calles, sigue en las barricadas, se escucha el grito en el campo de Marte; "el pueblo unido, jamás será vencido". Avanzan las protestas, se suman las regiones y siguen en pueblos y localidades. Se oye como explota la ciudadanía y como telón de fondo la letra de "El derecho de vivir en paz", el asesinado cantautor Víctor Jara pone la banda sonora de este tiempo insurreccional, es el pueblo que pide derechos, pide justicia y pide paz.

Hoy, las mayorías se han tomado los espacios ciudadanos y hablan con claridad y lucidez. Más educación pública, más salud pública, mejores sueldos, nueva Constitución y todo ello se cristaliza con un rotundo; ¡Renuncia Piñera! Así, al final del día este pueblo quiere un nuevo Chile y ha demostrado que no se dejará subyugar y seguirá movilizándose. Quiere cambios profundos y no cuentos, quiere un proyecto social distinto que lo tenga como protagonista. Y ellos, los dueños de todo le temen al pueblo movilizado. La socialdemocracia de viejo cuño y la nueva vestida de pañoletas no saben qué hacer. Buscan fórmulas republicanas, escudriñan en Rousseau, en Montesquieu, y dicen que el pueblo demanda un nuevo pacto social.

Esta revolución es profunda y genuinamente democrática. La marioneta de la “democracia chilena" creada en dictadura sucumbe. La burguesía y sus cómplices buscan por todos los medios convencer a un pueblo indignado que el futuro va ser mejor si se confía; ¿Si se confía en qué? 
Como lo dijera con una simpleza y una lógica abismante un poblador; "no fueron 30 pesos, fueron 30 años de abuso". Si esto no es una insurrección; ¿qué es? Es hora de definiciones y definiciones revolucionarias. Construir poder popular, poder en la base, el debate, el cabildeo y la movilización permanente, el juicio a la derecha y su salida del poder y, como corolario y demanda estructural, el fin del modelo neoliberal, fases de insurrección popular que se van instalando lenta pero inevitablemente, consolidar esas etapas es hoy y en las próximas horas la esforzada y noble tarea de quienes quieren y necesitan estar en esta luminosa vereda de la historia.

\section{CHILE Y SU CRISIS INSTITUCIONAL; ¿QUÉ NOS ESTÁ PASANDO?}

Chile se estremece en un estallido social sin parangón por lo intenso y lo extenso. Y a la pregunta; ¿qué nos está pasando? se pueden aventurar algunas respuestas dependiendo qué actores participan y sobre quiénes posemos la mirada.

Miremos a la derecha y al gobierno. Todos ellos están absolutamente confundidos con un poder que se les diluye y escapa entre los dedos. En caída libre en la percepción social de la ciudadanía. Han estado enfrascados en un duro debate entre personeros que quieren un acuerdo con pacto social, y los otros, no pocos, que quieren responder a la usanza tradicional con el uso del garrote, la zanahoria y tirar de las riendas militares para pacificar las calles. El presidente -por su parte- no sabe qué hacer, un día está por una armónica paz social y al otro por una violenta represión a la usanza dictatorial. Pero claro, lo común en ellos es que no quieren dar respuesta a las demandas sociales, sus propuestas han sido con letra chica y pateando la pelota al córner. Por su parte, la burguesía económica está expectante en sus sillones gerenciales, preocupados por la inoperancia del gobierno para resolver el conflicto.

Miremos ahora al parlamento. Aquí, el hemiciclo de la democracia está cada vez más confundido. Un grupo importante de parlamentarios de oposición junto al oficialismo apostaron a un pacto por la paz y se proyectaron como los salvadores del momento. La ciudadanía simplemente no les creyó, y ¿por qué no les creyó?; la respuesta es simple, porque se han matriculado siempre con respuestas mediáticas sin capacidad de generar credibilidad ni menos confianza ante el pueblo movilizado. No nos olvidemos que el parlamento tiene una aprobación 
promedio de 3 puntos $^{3}$. En estos días se han encontrado con un torbellino de proyectos de ley que, en vez de apuntar a una solución, al parecer y en la percepción de la ciudadanía, esas iniciativas legislativas van alejando y empeorando esas posibles soluciones.

Y miremos al pueblo movilizado. La Mesa de Unidad Social ${ }^{4}$ llama nuevamente a desplegarse con marchas y paros. Las personas han perdido el miedo y ahora se movilizan hasta en los centros comerciales del barrio alto, incluso en La Dehesa ${ }^{5}$. Cada vez se escuchan más voces que es ahora o nunca; 'es hoy cuando tenemos que ganar algo, y si no ganamos nada van ser otros 40 años más de abusos'. Hay claridad diáfana en las demandas políticas y sociales. Al parecer, en el movimiento social, pese a que es muy diverso y amplio, tienen más claridad que un pequeño puñado de la elite encapsulado en el gobierno y en el parlamento.

\section{LA VIOLENTA DIFERENCIA ENTRE CAPITAL Y TRABAJO EN LA DEMOCRACIA CHILENA}

Para entender esta realidad, es menester comprender que cuando en Chile se habla de democracia, un sector social enfatiza sobre el eje de la libertad de elegir, sobre la libertad de emprender, de tomar decisiones, sobre todo, es la libertad de movilizar el capital por todos los escenarios de la sociedad, así, desde esta perspectiva todo lo que huela a esa libertad es democrático. Parece ser una verdad esculpida en piedra a sangre y fuego. En particular, la derecha y los sectores liberales defienden esta concepción, aunque estos principios fueron fundados legal e institucionalmente durante una de las más cruentas dictaduras de América Latina. Esta idea de libertad siempre ha gravitado hasta hoy entre nuestra burguesía criolla.

Pero, cuando definimos la democracia desde donde debe considerarse a los no invitados, a las mayorías silenciadas, a los dueños y dueñas de la fuerza de trabajo, a los explotados y

\footnotetext{
${ }^{3}$ Diversas encuestas realizadas entre los meses de octubre 2019 a enero 2020 muestran esta tendencia de aprobación.

${ }^{4}$ La Mesa de Unidad Social son una agrupación de organizaciones sociales y territoriales, aproximadamente sobre 200, entre las más importantes están la Central Unitaria de Trabajadores (CUT); Colegio de Profesores; Federaciones Estudiantiles secundarias y universitarias; Organizaciones Feministas y Organizaciones de Pobladores entre otras.

${ }^{5}$ Sector territorial donde viven parte de los más ricos en Santiago de Chile.
} 
explotadas, a los trabajadores y trabajadoras, a los que siempre han existido en la historia de nuestra república pero que han sido invisibles y reprimidos brutalmente, allí, emerge la soberbia intolerante de la oligarquía. De esta manera, los trabajadores comienzan a caracterizar la democracia como la lucha por la igualdad, por el derecho a la vivienda, por el derecho a la salud, por el derecho a la seguridad social, así, la libertad se convierte en el medio oportuno y necesario para organizarse y luchar contra sus opresores que históricamente son y han sido los dueños del capital.

De este modo, llegamos a comprender que la democracia chilena actual sólo es una construcción cultural que nace de este perverso criterio acerca de la libertad de tránsito, movilidad e influencia del capital en la sociedad, estamos hablando de una democracia cooptada por la burguesía y su identidad; el capital. El ejemplo más nítido de ello es que cualquier gran empresario en Chile puede ser dueño de minas de cobre, propietario de bancos, propietario de empresas de distribución de bienes y servicios, de recursos naturales tan básicos como el agua, también ser propietario de canales de televisión y toda la influencia mediática que ello implica. Esta es la más nítida libertad del capital a la que le resulta tan funcional este tipo de democracia.

Por el contrario, a los trabajadores se les coarta la libertad de organizarse en sindicatos, no se les permite constitucionalmente representar políticamente a la ciudadanía, a sus pares, se les persigue si alzan muy fuerte la voz y se les encarcela si llaman a la movilización activa en pro de sus demandas más básicas, como son tener sueldos dignos y mejores condiciones de trabajo. No les permiten la negociación colectiva por rama de la producción, y suma y sigue. De esta manera, para los y las trabajadoras esta forma de "libertad democrática" que tanto profesa la derecha es un burdo engaño y carece de toda credibilidad.

Todo sistema democrático necesariamente se debe sustentar en las mayorías. Esas mayorías que -quiéranlo o no los dueños del capital- son las propietarias de la fuerza del trabajo, y esas mayorías hoy en Chile no se expresan, no pueden expresarse de manera alguna en ninguna estructura democrática del país y esta es nuestra realidad. Esto es lo central que se debe abordar seria y urgentemente para solucionar la crisis actual, todo lo otro acerca de las demandas sociales también es apremiante y se deben enfrentar, pero, para que las grandes soluciones sean sostenibles y se consoliden en el tiempo, se deben resolver los gigantescos y violentos desequilibrios 
institucionales de nuestra democracia que hoy existen entre los divergentes protagonismos del capital por una parte y del trabajo por la otra. Esta es la madre de todas las desigualdades de nuestra sociedad.

\section{EL CAMINO INSTITUCIONAL DE LA DERECHA NO ES LA RESPUESTA QUE ESPERA CHILE.}

Lo sabemos, la derecha no le responderá al país. La derecha dice hoy que las demandas sociales se resuelven con ajustes ministeriales, con disponibilidad de nuevos fondos públicos y uno que otro maquillaje al modelo neoliberal, incluso, hasta están dispuestos a una que otra reformita constitucional. Esa es su tesis principal y para ello invita a sus próximos, los socialdemócratas, y los convoca a debatir y a inventar una salida a esta crisis insolente e inesperada que les desbaratan las estanterías de su oasis ${ }^{6}$.

Pero, quienes conocemos a la derecha desde los tiempos de la dictadura, desde antes, desde siempre, sabemos que este gobierno de derecha solo busca ganar tiempo con estas reuniones de cafecitos y galletas. Su verdadero objetivo es lograr una nueva correlación de fuerzas, para implementar su estrategia y superar la crisis teniendo como norte permanente la sostenibilidad política del modelo neoliberal y darle un nuevo rostro de legitimidad, este modelo al que en las calles de Santiago y de regiones cientos de miles de mujeres y hombres, millones, le han dicho basta y ya no más, no más a una sociedad de abusos sino una sociedad de Derechos en un nuevo Pacto Social.

Quienes han aceptado “dialogar” con la derecha le están dando la espalda a la gente y a la insurrección popular. Ellos asumen y comparten la estrategia de la derecha en forma simbólica. Tendrán muchas respuestas que dar respecto de cuáles son sus motivos para hacerlo, pero, finalmente algo queda claro, la de estos "opositores" es una jugada arriesgada -sobre todo- cuando el movimiento social se autoconvoca y define que el problema son las elites políticas que no han estado a la altura de las exigencias populares. Mas bien, se percibe que todos quienes han ido a estas reuniones en La Moneda no les interesa el movimiento social, lo que verdaderamente les

\footnotetext{
${ }^{6}$ Se hace referencia a este concepto de oasis, concepto utilizado por Sebastián Piñera para referirse a Chile con respecto al resto de los países de América Latina. Chile el oasis de América Latina.
} 
importa es mantener la sacrosanta institucionalidad del poder conservador del sistema político chileno, y que se expresa en su catecismo ideológico que es la Constitución dictatorial.

De esta manera, podríamos colocar una apuesta subjetiva sobre la mesa; "quienes conversan con el gobierno diseñando posibles soluciones de cocinería y demagogia le tienen miedo al pueblo movilizado, pánico a las masas irreverentes, duras y críticas, resueltas y decididas y, definitivamente, no les gustan las formas ni el fondo de la crítica popular". Así, las élites por 30 años jugaron a la autosuficiencia y al paternalismo desde el Campus de Platón y hablaron en nombre del pueblo, nuestra elite política se convirtió en el oráculo de nuestra sociedad. Pero, cuando el pueblo se levantó ha dicho fuerte y claro; "un camino nuevo para Chile, no más deliberación en los salones de la burguesía, diálogo popular en cada plaza, en cada población, ya no hablen por nosotros, sino que desde ahora hablaremos por nosotros mismos".

Excluir de este debate crucial a las organizaciones populares es hacerle el juego a la derecha, es hacerles el juego a los poderosos del país. La Mesa de Unidad Social que agrupa a organizaciones sociales y sindicales reales demanda un nuevo país, nuevas bases institucionales, nueva constitución, una nueva democracia con base popular y no cupular. Hay que avanzar tras esta Unidad Social que es la unidad de la sociedad en su conjunto, convocando y llamando a plebiscitar la elaboración de una nueva Constitución Política y que su método de construcción sea a través de una Asamblea Constituyente. Esta es la identidad de este Chile nuevo y distinto, inclusivo, popular, solidario, comunitario, soberano, autónomo, que deja atrás un modelo social y económico depredador e inhumano, para levantarse sobre sólidos pilares democráticos y ahora sí, porque la esperanza ya no se deposita en otros, sino que ahora descansa en las propias capacidades del pueblo, este es el Chile de hoy, nada más y nada menos.

\section{LA VIEJA ESTRATEGIA DE CRIMINALIZAR LAS MOVILIZACIONES SOCIALES.}

Entretanto, la derecha chilena da muestras de su carácter antidemocrático y persecutor de los movimientos sociales. Sobrepasada por las actuales movilizaciones populares y sin capacidad de dar respuesta política a las demandas de la ciudadanía, la derecha no duda en tomar las riendas de la represión y adecuar la construcción jurídica del país para criminalizar las manifestaciones 


\section{Revista \\ Debates Insubmissos}

sociales legítimas y democráticas, y que hoy han adquirido una connotación multitudinaria extensiva a todo el territorio nacional.

De esta manera, propone al congreso legislar proyectos de ley como la ley "antiencapuchados", la ley antisaqueos y antibarricadas, que endurecen sanciones a delitos de robo en medio de situaciones de calamidad pública o de grave alteración al orden. ¿Cuáles son los riesgos de esta "nueva legislación"? Primero, condicionar la forma de realizar las movilizaciones sociales que, como cualquier fenómeno social de manifestación colectiva, se da mayoritariamente en un marco de paz y tranquilidad. Pero, la constatación histórica muestra que estas concentraciones masivas pueden ser presa de provocadores y de intervenciones policiales "de inteligencia", que buscan incitar a desmanes y acciones violentas. Por tanto, los asistentes quedan expuestos a posibles montajes que podrían traer graves consecuencias legales afectando el futuro de una persona, sobre todo cuando los afectados pueden ser jóvenes y estudiantes. Segundo, incrementar la sanción de formas de interrupción del tránsito público por medio de barricadas y otros instrumentos, es simplemente terminar con el derecho a manifestarse en las calles del país. Quizás, lo que pretende la derecha es que las manifestaciones públicas sean solo en recintos cerrados. Tercero, la ley antisaqueos es claramente un delito penal que no tiene porqué vincularse a la movilización social. Se debe mejorar su descripción y sus sanciones y de ello no cabe duda, pero no tiene porqué vincularse conceptual y simbólicamente a manifestaciones sociales públicas.

Debemos establecer una muy seria alerta sobre los riesgos de estos "mejoramientos" legales. Como ya sabemos y de manera trágica, a renglón seguido y como ha ocurrido a lo largo de la historia de Chile, se establecerá que ya no es suficiente tener mejores normas y más claras en sus sanciones, sino que en el debate político y jurídico de la derecha y sectores conservadores, se instalará la perversa idea de no solo perseguir al que realiza materialmente "el delito", sino a quien convocó a la movilización, al "instigador", a los que subieron al estrado a "azuzar a las masas", es decir, dar píe a iniciar la persecución penal o más bien política a las y los dirigentes sociales y sindicales. Esto es y finalmente, criminalizar las demandas populares e iniciar un ciclo de persecución política en Chile a todo lo que huela a dirigencia social critica democrática. Según nuestra propia memoria histórica, sabemos que esto puede terminar con dirigentes sociales y 
sindicales en las cárceles y, por tanto, haciendo de la democracia como sistema político apenas un feudo privado de los poderosos de siempre y de su institucionalidad una triste caricatura administrativa funcional a sus intereses.

\section{EN EL PAÍS EN QUE SE DEBE PAGAR HASTA POR PROTESTAR}

Debemos prestar atención a que -hasta ahora- las propuestas elaboradas por el gobierno han sido dentro de los marcos y reglas institucionales del modelo de desarrollo neoliberal, todas ellas. Han echado mano a instrumentos como bonos, subsidios, incrementos, entre otros, y su implementación en algunos casos será por medio del escalonamiento en el tiempo del gasto, como por ejemplo en el caso de las pensiones de los adultos mayores. Todos estos instrumentos son discrecionales a la orden del ejecutivo cuando y como se deben otorgar, y cuando se deben suspender o simplemente anular. La idea es validar el olfato del empresario especulador en finanzas, pues, la hipótesis detrás de estas acciones de políticas públicas para implementar en nuestro país, es simplemente especular con la solución esperando que los "rotos" se calman con estas aspirinas.

La derecha, y en particular el empresario Piñera, leen que no le pueden dar paso a las reformas estructurales y al cambio del modelo neoliberal por una razón obvia, el empresario Sebastián Piñera se enriqueció con el modelo y hoy tiene una fortuna de más de 2.700 millones de dólares no solo por sus conocimientos y acciones financieras "exitosas", sino también, porque el modelo le da ventajas para la acumulación y la concentración de sus riquezas. En términos empresariales sin duda que él mismo es un resultado explícito del modelo, y nadie objetivamente podría creer que una persona que se ha enriquecido gestionando el modelo neoliberal lo quiera cambiar reconfigurando su naturaleza. Desde un punto de vista de simple racionalidad lógica, sería "suicidarse" al negar el rol de su identidad y de su historia personal.

Por estas razones, las propuestas que hace su gobierno -en términos de financiamiento fiscal- vienen del mismo presupuesto público, por medio de reasignaciones y/o endeudamientos que se van financiar con ingresos del Estado; ¡y aquí está lo grave! Los ingresos del Estado, que financian el presupuesto de la nación en un 50\% provienen del Impuesto al Valor Agregado (IVA) que lo pagan todos y todas las chilenas. Sólo un dato, más del $90 \%$ de la población chilena 
consume la totalidad de sus ingresos, por lo tanto, más del $90 \%$ de la ciudadanía paga IVA y terminará financiando esas magras limosnas llamadas "agenda social".

Esto explica por qué la derecha se ha negado rotundamente, y en los hechos, a financiar las medidas de su "agenda social" con cambios reales y potentes en la estructura de financiamiento del presupuesto fiscal. Y esto viene a significar que por ninguna razón quiere terminar de verdad con las desigualdades de nuestra sociedad, los ricos no van a poner ni un peso para financiar nada, y entre los más ricos está él, el empresario Piñera. Esto es indignante después de 4 meses de protestas en las calles. Esto es seguir humillando a los más pobres de Chile, al pueblo. La síntesis de la derecha en los salones y pasillos del palacio de Gobierno hoy es muy simple; "los que protestan pagan".

\section{EL PARO NACIONAL Y EL FALLIDO "ACUERDO POR LA PAZ"}

Desde las primeras horas de la mañana del martes 12 de noviembre se dio inicio al Paro nacional productivo convocado por Unidad Social. Trabajadores y trabajadoras, pobladores y pobladoras, múltiples organizaciones sociales, culturales y territoriales, avanzaban ocupando las anchas alamedas en todo el país. Se vieron marchar sindicatos del sector privado que por primera vez se plegaban a una movilización nacional, sindicatos del sector público, colegio de profesores, estudiantes, la Coordinadora No+Afp, agrupaciones artísticas, movimientos feministas en todas sus expresiones, era un pueblo marchando resuelto y convencido. Todo en paz y con una lúcida claridad en sus demandas y con una resuelta fuerza en su disposición. El discurso de cierre de este Paro Nacional fue un llamado claro y preciso; ¡iNueva Constitución por medio de Asamblea Constituyente!! Y las movilizaciones continuaron todo el día, una jornada más de lucha en donde el pueblo termina defendiéndose con coraje y valentía popular ante la desbordada y brutal represión policial.

Una vez más se alzan las y los trabajadores, es el pueblo en su conjunto con sus hijos. La derecha, claramente atemorizada responde desde La Moneda buscando una salida, respuesta que fue al más puro estilo patronal y prepotente sin cambiar en nada su guion genético e histórico, Sebastián Piñera, nervioso y disperso sale a llamar a "la paz" y poner fin a la violencia, así, propone un acuerdo político, pero advierte que si no hay acuerdo habrá persecución a los 


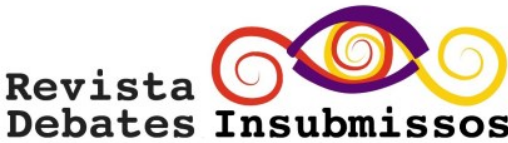

instigadores, a los que azuzan, a los que incendian la pradera y provocan que se alcen los de abajo, los nadie, que se alce el pueblo. Y hasta hoy, silencio cómplice y criminal respecto de las y los muertos, de las y los mutilados, de las y los torturados y violados, que los órganos represivos bajo su mando como jefe de Estado han cometido como autores y responsables.

Reacciona el gobierno y alinea a los partidos de derecha, suma a algunos partidos de oposición, a los vacilantes de siempre y todos corren por los pasillos del congreso a tomar algún acuerdo que les permita respirar y ganar tiempo. Hacen la parodia del debate, del acuerdo refundacional, del acuerdo histórico, del acuerdo salvador de la patria y de la democracia. Increíblemente, se unen perseguidores y perseguidos en la historia reciente de Chile. Y la máxima moral para justificar este comportamiento es que Chile está primero; ¿cuál Chile? nos preguntamos; pues, el Chile de los privilegiados e intocables, el Chile accionario y gerencial, el Chile paltón y patronal. Porque el Chile popular, el Chile de las mayorías, el Chile que está luchando por cambios profundos sólo con sus manos y sus pies, sólo con su coraje y sus convicciones, ese Chile, en verdad, no se veía por ninguna parte en estas reuniones de salón en uno de los palacios del poder. Palmoteos y sonrisas eran la tónica. La derecha exultante porque finalmente repetía exitosamente la fórmula que tantos dividendos le ha dado en los últimos 39 años, ganar con la pequeña y mágica fórmula en donde el 33\% manda al 66\%, fórmula inaugurada desde la dictadura.

Y apenas horas después de ese sigiloso y turbio acuerdo, el pueblo se volvió a movilizar masivamente y demostró nuevamente que por ningún motivo ni razón está disponible para pactos a sus espaldas y entre cuatro paredes. La solución es cada vez más clara para el pueblo; Plebiscito consultando por el cambio a una nueva Constitución, elección directa de los miembros de una Asamblea Constituyente y, ratificación por medio de otro Plebiscito para sancionar la nueva Constitución que se proponga. Dejando claro que los acuerdos deben ser de mayoría y no de las minorías como lo propone este acuerdo por "la paz", que no es otra cosa que un burdo arreglo desde el poder para intentar salir huyendo de la crisis, sin entender aún, que la única salida razonable y definitiva es poner fin a los males de la desigualdad que aquejan hoy a Chile y que parten por una nueva Constitución. 


\section{LA DERECHA DURA NO DA PIE ATRÁS.}

Hoy, en la derecha se están pronunciando los duros, los pinochetistas de siempre, los que se amparan y atrincheran en la obra de su general, los que defienden la Constitución del ' 80 a rajatabla. Son aquellos que se visten con ropaje demócrata pero que no dudan un segundo en defender el modelo neoliberal impuesto por la dictadura militar a sangre y a fuego. Dejaron avanzar expectantes y con desconfianza el "acuerdo por la paz", acuerdo que, mirado a contraluz, se perfiló inmediatamente como débil, sospechoso, poco claro y condicionado por las minorías de derecha. Creyeron -junto a los sectores de oposición que participaron de ese acuerdo-, que estampando sus firmas y con la venia del gobierno todo se iba a detener en las calles de Chile, que se acabaría la movilización popular. Pero, a la luz de los acontecimientos y de los porfiados hechos, el tristemente famoso acuerdo no pasó la prueba de la blancura y el pueblo sigue movilizado. El movimiento social de nuestro país, aprendió heroicamente en estos días, que una mentira es suficiente hasta para poner en duda cualquier intención de verdad.

Esto lo observó la derecha dura, la derecha miliquera y neoliberal, la intransigente, y salió al ruedo con todo su poder simbólico autoritario. El senador Andrés Allamand (RN) amenazó con la continuidad de la Constitución del '80 planteando en el diario "La Tercera" que; "si no se alcanzan los 2/3 para ninguna de las normas, fracasó la convención, si fracasó la convención no hay plebiscito de ratificación, y si no hay plebiscito de ratificación -aunque a algunos les molesteno hay nueva Constitución. Por lo tanto, rige la Constitución vigente".

La presidenta de la UDI -por su parte-, aseveró en Radio Duna respecto de votar No, que; "estoy absolutamente convencida de que este cuerpo legal, más allá de las críticas que se le puedan hacer, es un cuerpo legal que le ha permitido crecer al país en los últimos 30 años. Ha permitido que mucha gente que estaba en la extrema pobreza hoy sea de clase media. Decidimos hacer esa pregunta de optar por la actual Constitución porque creemos que es legítimo que las distintas opciones se transparenten".

Asimismo, José Antonio Kast anunció que pretende defender la actual Constitución de 1980, en declaración de su colectividad -el partido Republicano- señaló; "la actual Carta Magna es un instrumento que le permitió a nuestro país ser la nación más exitosa de la región, librando a millones de chilenos de la pobreza extrema y construyendo bases sociales, económicas y 
políticas sólidas que son garantía de un país serio", declaraciones recogidas por radio Biobío respecto de ese bando militar llamado Constitución del ' 80 , y que fuera confeccionado y aprobado en dictadura sin ninguna norma democrática que la legitime.

De estas declaraciones solo se desprenden perfiles autoritarios y dictatoriales, y consecuentemente con ello, defienden el legado de la Constitución de Pinochet y para ello no trepidan en amenazar. Creer que se van a someter fácil y dócilmente a un acuerdo que ya es ventajoso para ellos, es no entender el origen y la historia política que defienden. Saben que deben ganar tiempo para convencer a otros sectores que el mal está en las calles y que se requiere más fuerza y más represión para detener la protesta política. Su fórmula es golpear al pueblo. Pero, para eso necesitan el consenso de los dueños del capital y de quienes tienen el poder de fuego. Tienen todo el deseo de avanzar en esta estrategia y es claro que no se detendrán.

\section{MOVILIZACIONES Y PERCEPCIÓN SOCIAL; ¿QUÉ NOS DICEN LAS ENCUESTAS?}

Durante los últimos 4 meses no se han dejado de hacer encuestas. Todas ellas han captado el momento político y social que vive el país y cada una de ellas ha tenido distintos énfasis. Intentaremos resumir sus resultados y ponerlos al trasluz para saber qué camino está tomando la sociedad chilena ${ }^{7}$.

Las encuestas que se revisaron son; (1) el 'Termómetro Social' de Octubre 2019, realizada por el Núcleo Milenio en Desarrollo Social y el Centro de Microdatos de la Universidad de Chile; otra encuesta que se ausculta es (2) 'Crisis en Chile'; evaluación de las manifestaciones, medidas de gobierno, desempeño de instituciones y percepción de la militarización, de la empresa Activa Research del 24 de octubre; otra encuesta que utilizaremos es de la misma empresa, (3) 'Pulso Ciudadano' de Octubre del 2019 publicada el 6 de noviembre; asimismo, sumaremos las encuestas de la empresa Criteria Research, una, titulada; (4) 'La Crisis Social en Chile' de octubre del 2019, que evalúa la percepción de las medidas anunciadas por el gobierno entre el 25 y 29 de

\footnotetext{
${ }^{7}$ Un elemento metodológico que se debe tener en consideración para este análisis de encuesta. Los resultados no se comparan entre encuestas, solo se describen los componentes, variables y sub variables de cada encuesta todo con el objetivo de dar una mirada panorámica de las tendencias en que se mueve la percepción social en medio del conflicto.
} 


\section{Revista \\ Debates Insubmissos}

octubre y, la otra de la misma empresa, su encuesta (5) 'Agenda Ciudadana' de Octubre del 2019, publicada el 4 de noviembre.

Al medirse el apoyo ciudadano a las movilizaciones da como resultado entre un $85,8 \%$ y un 83,6\%de apoyo. En esta misma línea, la encuesta 'Crisis Social' de Criteria Research, muestra como resultado al aplicar la pregunta; ¿con cuál de estas frases te sientes más identificado/a? el $79 \%$ de los encuestados se inclinó por la frase: "creo que las movilizaciones van a tener consecuencias positivas y las cosas van estar mejor en el país". No hay duda que las movilizaciones no sólo por su masividad en las calles tienen un apoyo mayoritario, sino que, también, por una positiva percepción social, es decir, el que no se moviliza también apoya.

Como resultados desagregados en términos de grupos socio económicos se da que el nivel C1 (de mayores ingresos) es el más bajo en apoyo, 75,5\%; los niveles D y E (de menores ingresos), un $86,5 \%$. Así, solo hay 11 puntos porcentuales entre los segmentos sociales más acomodados y los más pobres, es decir, socialmente es una demanda transversal. En términos de edad, los jóvenes registran un apoyo de un $87,5 \%$ y las personas de más de 50 años apoyan en un $82,7 \%$, solo 5 puntos de diferencia entre los más jóvenes y los más viejos, lo que ratifica la transversalidad de las demandas. Los hombres y las mujeres con un $85,5 \%$ y un $81,9 \%$, respectivamente. En términos de zonas geográficas; (a) Norte, 89,9\%; (b) Centro, 81,6\%; (c) RMS, 79,6\% y (4) Sur, 88,8\%. Otro dato importante que entrega esta encuesta, es que el 90,5\% de los encuestados está de acuerdo cuando las manifestaciones son pacíficas.

Los principales conceptos que motivan el apoyo a las movilizaciones son; desigualdad, justicia y descontento. De sus encuestados, el 55,3\% ha participado en algún tipo de movilización. De los cuales el $71,7 \%$ en cacerolazos, el $61,4 \%$ en marchas y concentraciones y un $58,6 \%$ en redes sociales.

Los resultados muestran que las principales motivaciones que ha tenido la ciudadanía para movilizarse son: (1) Sueldo de los trabajadores, 87,1\%; (2) Precios de los servicios básicos (luz, agua, gas), 86,3\%; (3) Pensiones de los jubilados/as, 85,7\%; (4) Desigualdad económica entre los chilenos, 85,2\%; (5) Costo de la salud en Chile, 79\%; (6) Precio del transporte público, 76\%; (7) Alza de la tarifa del metro, 72,4\%; (8) Precios de los medicamentos, 72\% y (9) Costo de la educación, 71,2\%. Estos son los nueve factores que los ciudadanos reconocen como importantes 


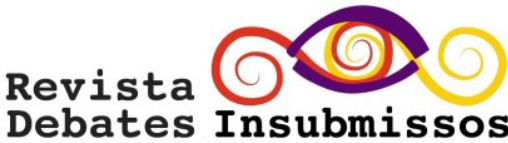

y necesarios motivos para movilizarse. También se reconocen las sensaciones y sentimientos que se han generado para movilizarse, los 5 más importantes según las y los encuestados son: (a) Rabia, 53,3\%; (b) Inseguridad, 50,4\%; (c) Tristeza, 49,3\%; (d) Esperanza, 33,5\% y (e) reflexión, $32,1 \%$.

La encuesta Pulso Ciudadano del mes de octubre de Activa Research, dio a conocer la percepción de las medidas propuesta por el gobierno, de menor a mayor apoyo fueron las siguientes: (a) El Ingreso Mínimo Garantizado de \$ 350 mil, 21,6\%; (b) Aumento de Pensiones de Vejez, 23\%; (c) Seguro que cubre parte del gasto en medicamentos, 27,4\%; (d) Seguro de Enfermedades Catastróficas, 28,1\%; (e) Convenio de Fonasa con farmacias, 32\%; (f) Defensoría de las Víctimas, de forma de fortalecer la defensa jurídica y de apoyo a las víctimas de la delincuencia, 38,4\%; (g) Impuesto Global Complementario de $40 \%$ para las rentas superiores a 8 millones mensuales, 39,5\%; (h) Estabilización de las tarifas eléctricas, lo que permitirá anular la reciente alza del 9,2\% de la electricidad, 39,8\%; (i) Fortalecimiento del Fondo Común Municipal, estableciendo mayores aportes de las comunas de mayores ingresos a las comunas de menores ingresos, 45,54\%; (j) Proyecto Pro-Infancia, que termina con Servicio Nacional de Menores y lo reemplaza por dos nuevos servicios públicos, 47,2\%; (k) Plan de Reconstrucción de los daños y destrucciones provocados por la violencia y delincuencia ocurridas en los últimos días, 47,5\%; (1) Proyecto que establece la reducción de las contribuciones de los adultos mayores más vulnerables, 51\%; (11) Proyecto que crea el derecho a la Sala Cuna Universal para todos los niños de madres o padres que trabajen, 61\% y (m) Reducción de las dietas de los parlamentarios y de los altos sueldos de la administración pública con reducción en el número de los parlamentarios, $65,8 \%$.

En síntesis, las encuestas muestran que la salida que diseñó el gobierno no tuvo el mismo apoyo mayoritario que las demandas y motivaciones de la ciudadanía para movilizarse. Por tanto, no fueron en ninguna medida una solución a la crisis, así, como se ha ido percibiendo después de las movilizaciones, éstas no bajan en su desarrollo y el apoyo de la ciudadanía sigue manteniéndose.

Por su parte; la encuesta TSUChile de la Universidad de Chile señala que las principales instituciones que generan confianza en la ciudadanía (escala de 1 a 10 , donde 1 es menor confianza y 10 mayor confianza) son: bomberos, 9,4; organizaciones voluntarias de ayuda y 


\section{Revista \\ Debates Insubmissos}

ONG's, 7,2; juntas de vecinos y organizaciones territoriales, 6,3; hospitales, 6,2; Instituto de Derechos Humanos (INDH), 6,0; Sindicatos y Gremios, 5,7; Alcaldes, 4,4; Carabineros de Chile, 3,8; Organizaciones religiosas, 3,7; FF.AA., 3,7; Tribunales de Justicia, 3,4; Empresarios, 3,2; Presidente de la República, 2,8; Ministros (as), 2,6; Parlamentarios, 2,5 y Partidos Políticos, 2,4.

Cabe señalar que la ciudadanía confía en todas aquellas instituciones cuyos objetivos sean la defensa y ayuda social a las personas, tal y como como lo indican los datos expuestos anteriormente. Es interesante observar que las juntas de vecinos y las organizaciones territoriales, como también las organizaciones sindicales y gremiales, tienen un nivel de confianza para la ciudadanía que sobrepasa con creces a la confianza que se le tiene a la institucionalidad pública y al sistema político. Esto permite inferir que, en general, las personas no han dejado de creer en las organizaciones que las potencian comunitariamente en la búsqueda de la solución de sus problemas sociales. De la misma manera, las personas en su condición de trabajador o trabajadora mantienen la confianza en las organizaciones sindicales como instrumentos para conseguir mejores condiciones laborales y, por tanto, de mejoría en su calidad de vida. Es importante concluir que aun la sociedad chilena cree que las luchas sociales deben ser por medio de sus propias organizaciones y las capacidades que estas potencian en sus acciones colectivas.

Lo anterior se refleja en los datos que emanan de las respuestas a la siguiente pregunta; ¿Organización en la cual confiaría más como mediadora entre Gobierno y movimiento social? Las organizaciones en las cuales confiarían son; Organizaciones Sociales, 31,6\%; Agente Internacional, 17,6\%; Alcaldes, 11,1\%; Universidades, 10,1\% y Sindicatos, 9,2\%. Cabe destacar que las organizaciones en que menos confía la ciudadanía son los Partidos Políticos, 4,2\% y la Iglesia $2,9 \%$.

Ante la protesta y demanda política que actualmente cursa en Chile la sociedad manifiesta su desconfianza en el sistema político y en cada uno de sus componentes, como son los partidos políticos y el poder ejecutivo. Pero, claramente, abre el espacio para la negociación a través de sus propias organizaciones, sean estas organizaciones sociales -territoriales y/o sindicalesgremiales. Por tanto, las organizaciones sociales y sindicales agrupadas en la Unidad Social son claves en el desarrollo de las demandas y en el proceso de la negociación con el gobierno. Ahora, 


\section{Revista \\ Debates Insubmissos}

este último, el gobierno, insiste en buscar una solución al interior del sistema político, no observando que la ciudadanía no confía y no le cree.

La encuesta de la Universidad de Chile consulta sobre; ¿Cuán conforme o disconforme está usted con la actual Constitución? Entre las variables (a) muy disconforme (46,2\%) y (b) disconforme (30,5\%) suman un 76,7\% de las y los consultados sobre su nivel de inconformidad con la actual Constitución. De la misma manera, se consulta; ¿Cuán importante considera usted que es para el país que se cambie la actual Constitución? Entre las variables (a) muy importante $(66,1 \%)$ y (b) bastante importante $(14,6 \%)$ suman el $80,7 \%$ de las y los consultados sobre su parecer acerca de lo importante que es que se cambie la Constitución. Se continúa con el acuerdo o desacuerdo personal en que cambie la Constitución, entre las variables (a) totalmente de acuerdo $(63,1 \%)$ y (b) de acuerdo $(20,8 \%)$ suman el $83,9 \%$. Sobre el mecanismo por el que se inclinan las y los consultados es claramente mayoritaria la variable que se define como; "una asamblea constituyente para que redacte una nueva Constitución”, con un 75,7\%.

La última encuesta del Centro de Estudios Públicos -CEP- que fue realizada entre el 28 de noviembre 2019 y el 6 de enero 2020. Y se destaca la fecha de realización de la encuesta porque en ese periodo, que incluye todo diciembre, casi toda la "elite" política e intelectual de gobierno y los sectores socialdemócratas aledaños apostaron a que la movilización social y las demandas decaerían y terminarían diluyéndose. Ello explica que el gobierno respondiera al estallido popular con una agresiva agenda legislativa antimovilización endureciendo y reconceptualizando delitos para criminalizar la protesta social. De la misma manera, conspicuos personajes de la centroizquierda, conocidos en su momento como el partido transversal del orden, escribieran furibundas declaraciones para condenar la violencia en las movilizaciones sociales, haciéndole el juego a la derecha bajo la misma hipótesis de que en diciembre el pueblo movilizado retornaría a sus poblaciones cansados y derrotados.

Nada de eso ocurrió. El pueblo siguió movilizado de nuevas maneras reformulando su protesta. Manteniendo en alto las demandas y profundizando en la percepción social acerca de lo justo de ellas y valorizando la democracia en su concepción más legítima y más verdadera. Así lo muestran los resultados de la encuesta CEP. Cuando se pregunta por los tres problemas más importantes, se mantiene en primer lugar las pensiones, pasando de un $46 \%$ a un $64 \%, 18$ puntos 


\section{Revista \\ Debates Insubmissos}

más que la encuesta de mayo 2019, en segundo lugar, se mantiene salud, pasando de un $34 \%$ a un 46\%, 12 puntos más que la encuesta de mayo 2019, en tercer lugar, educación, pasando de un $30 \%$ a un $38 \%, 8$ puntos más que la encuesta de mayo 2019. Es importante hacer mención que el problema de la delincuencia, asaltos y robos, que en mayo 2019 era el primer problema de importancia para la ciudadanía, cae de un $51 \%$ a un $26 \%, 25$ puntos menos en esta encuesta de diciembre. Esto deja ver que la ciudadanía sigue teniendo clara sus demandas sociales, acrecienta y fortalece el mérito e importancia de las mismas y da cuenta -asimismo- de la NULA respuesta del gobierno a esas exigencias populares.

Chilenas y chilenos consultados advierten que el gobierno intenta detener la movilización, criminalizándola. y las personas en forma clara y precisa piensan que ese no es el problema de fondo. Más aun, la gente identifica que quienes participan de ese vandalismo que quiere asociarse con las protestas, son delincuentes (un 20\%) y lumpen (un 14\%), pero también emerge la respuesta que son personas cansadas de los abusos y la desigualdad (un 11\%). Por tanto, esta percepción no mancha ni desacredita la imagen positiva de la demanda social. Y en sentido contrario, el actuar de carabineros y militares han sido percibidos como crímenes hacia los derechos humanos de quienes protestan. El 64\% piensa que 'muy frecuentemente' y 'frecuentemente' (también se podría sumar el 24\% que reconoce que 'a veces'), carabineros violaron los DDHH. Por su parte, el 49\% piensa que 'muy frecuentemente' y 'frecuentemente' (también se podría sumar el 29\% de 'a veces'), los militares también violaron los DDHH. Hay que recordar que los militares sólo actuaron un par de semanas en las calles del país, eso podría estar influyendo en una percepción más baja que lo que se aprecia respecto al accionar de carabineros. Pero, lo importante es que ambas cifras son significativamente altas.

En síntesis, la percepción ciudadana acerca de responsabilidad y autoría en crímenes y delitos asociados con la movilización social, está en el lado de las instituciones que debe controlar el gobierno y no en la vereda del pueblo movilizado. Por su parte y al parecer, la interpretación de la realidad desde la elite, del gobierno y de sus asociados (también de "oposición"), tiene que ver mucho con el miedo cada vez más certero a perder privilegios concretos, a propósito de un pueblo luchando en las calles por más democracia y por más participación real en la toma de decisiones vinculadas al poder. 
Así, el pueblo movilizado les responde a las elites de derecha y socialdemócratas demandando más y mejor democracia. El 64\% de los encuestados y encuestadas considera que la democracia es preferible a cualquier otra forma de gobierno. Solo un $11 \%$ considera que la respuesta es un gobierno autoritario. Esto es lo que no lee la derecha con sus últimas acciones políticas de privilegiar medidas autoritarias. Por eso, el apoyo al presidente Sebastián Piñera es apenas un paupérrimo $6 \%$.

El $44 \%$ y el $47 \%$ de los encuestados y encuestadas consideran que la democracia actual en Chile funciona 'regular" y "mala' o 'muy mal', respectivamente, es decir; un 91\% de chilenas y chilenos no creen en el tipo de democracia que vivimos. De hecho, cuando se les consulta por la institución más representativa de una democracia como es el parlamento, el nivel de confianza es de un 3\%, esto es grave, porque puede ser hasta un $0 \%$ de confianza ya que técnicamente la encuesta tiene un margen de error de un 3\%. En el caso de los partidos políticos ese nivel de confianza es apenas de un $2 \%$.

Si se observa bien, tanto el ejecutivo como el congreso y los partidos políticos, entendidos como instrumentos cruciales de una democracia, están en el suelo desde el punto de vista de la confianza de la ciudadanía. Por esta razón, ciudadanos y ciudadanas de Chile creen que es necesaria una nueva carta constitucional, el 67\% la aprueba.

\section{ELECCIÓN DE ASAMBLEA CONSTITUYENTE; UN MECANISMO GENUINAMENTE DEMOCRÁTICO}

En estos últimos días, en nuestro país ha comenzado un intenso debate acerca de cuáles son los criterios más idóneos para la óptima elección de una asamblea constituyente, que sea lo más representativa posible de la diversidad social de nuestra comunidad y que exprese de la mejor forma las demandas de la sociedad chilena.

Algunos antecedentes a saber: la proporcionalidad de género en nuestro país es, según datos demográficos, las mujeres son 8.972.014 y corresponden al 51,1\% de la población total del país, y los hombres son 8.601 .989 y corresponden al 48,9\% de la población total del país. Por su parte; en lo que respecta a la proporcionalidad étnica, es el 12,8\% de la población, que es la gente 
que se considera perteneciente a un pueblo originario, es decir, son 2.249.472 habitantes (Fuente: INE; Informe Censo 2017).

El procedimiento para que se expresen estas proporcionalidades es: número mínimo de asambleístas; 310. Proporcionalidad de género: Mujeres; 158 (el 51,1\% de la asamblea), y Hombres; 152 (el 48,9\% de la asamblea). La proporcionalidad étnica señala 40 asambleístas (el $12,8 \%$ de los 310 ), y de esos 40, por paridad de género; 20 mujeres y 20 hombres.

El instrumento de elección debería ser un voto por lista nacional, por partido político, sociedad de partidos o por listas de hombre y mujeres independientes, también por lista de representación étnica, en caso de esta última, con un tope máximo de 40 candidaturas. La forma de inscripción para las listas de independientes y étnica debería ser con el 0,5\% de firmas de apoyo, porcentaje referido a la participación de los votos válidamente emitidos en la última elección parlamentaria de diputados a nivel nacional. Así, el requisito de participación sería recolectar 33.000 firmas aproximadamente a nivel nacional.

El mecanismo para definir quiénes son asambleístas en un sistema de proporcionalidad electoral perfecta o pura, y que tenga un carácter nacional, requiere una sola circunscripción nacional. Se definen como sistemas proporcionales puros (Israel, Holanda, Nicaragua) aquellos que aspiran a la proporción matemáticamente posible del conjunto de escaños disponibles (Nohlen, 1994 ed. Pp.74). La fortaleza principal para el caso de una Asamblea Constituyente es que: "nadie está excluido de la representación, las minorías pueden llegar a obtener escaños y como corolario de lo anterior, los electores que no optan por candidatos con posibilidad de obtener la mayoría de los votos siguen teniendo una voz para que sus preferencias puedan tener representación" (Colomer; 2004).

Para cumplir con la paridad de género y la proporcionalidad étnica, todas las listas deben ser inscritas ya habiendo aplicado ambos criterios en su presentación y diseño inicial de sus candidaturas. Listas cerradas por uno o más partidos, lista cerrada para independientes, lista cerrada étnica, una mujer, un hombre, hasta el cupo 310 en el caso que lo decidan así y, una mujer, un hombre, hasta el cupo 40 en lista étnica. La evidencia internacional muestra que este formato garantiza la representatividad más equilibrada entre hombre y mujeres. Ídem para el caso de la condición de género en el componente de representación étnica. 
El mecanismo de participación debiera ser con Voto Obligatorio. Y el voto se aplica a la lista. Esta elección pretende representación de ideas, porque el objetivo final de una asamblea constituyente es plasmar diferentes visiones de mundo en la Constitución Política.

Por último ¿cómo se eligen los asambleístas?, calculando la proporción obtenida por la lista de los votos válidamente emitidos. Posteriormente, se aplica el guarismo o porcentaje al total de cupos en la asamblea, así, se obtiene el número de asambleístas que cada lista elige. Posteriormente, se mantiene la jerarquía de presentación o prelación de la lista en el voto para definir quiénes serán las y los asambleístas. Al ser listas cerradas, conoceremos los nombres y rostros de quiénes serán las ciudadanas y ciudadanos constituyentes, quienes tendrán la responsabilidad histórica y señera de dotar a nuestra sociedad de normas de convivencia genuinamente democráticas como necesitamos y nos merecemos.

\section{SÓLIDAS RAZONES PARA ADELANTAR LAS ELECCIONES DE PRESIDENTE Y DEL PARLAMENTO.}

Desde hace algunos días, después de la entrega de los resultados de la encuesta del Centro de Estudios Públicos -CEP-, surge la inevitable conclusión de que nuestro sistema democrático está con serios problemas de legitimidad. La figura presidencial marca un 6\% de apoyo, el congreso apenas un 3\% de legitimidad y los partidos políticos solo un $2 \%$. En Chile, las tres instituciones más fundamentales e imprescindibles para el ejercicio de una democracia están en una crisis de legitimidad política muy grave e indesmentible. Pese a lo anterior, las élites de derecha en no lo quieren reconocer, es más, no lo consideran un factor gravitante a considerar, sobre todo, cuando hemos vivido más de 4 meses de movilizaciones sociales que luchan en las calles por demandas justas que aún no se responden satisfactoriamente. Por su parte, las élites socialdemócratas -en general- evitan la discusión o simplemente se quedan en silencio, por su responsabilidad política culpable y cómplice en no satisfacer las demandas de la ciudadanía cuando tuvieron el poder.

Pero, aún así, las personas consideran que la democracia es preferible a cualquier otra forma de gobierno (64\%), con un bajo porcentaje (11\%) de quienes creen que en ciertas circunstancias es preferible un gobierno autoritario. Por tanto, la salida a la crisis de legitimidad 
y para un buen funcionamiento de nuestra actual democracia, es insoslayable iniciar prontamente un proceso de relegitimación de las autoridades electas, y para ello, es necesario y urgente llamar a una elección de Presidente de la República y renovación del Parlamento.

Esta relegitimación democrática se hace totalmente plausible y evidente como necesidad republicana, sobre todo, cuando está en juego el cambio de la Constitución Política de Chile. ¿Por qué razones?: Primero; al tener actualmente autoridades con una nula o escasa legitimidad, es claramente inconveniente y difícil llevar a cabo un proceso constituyente de nuestra carta fundamental, porque ella requiere -como requisito básico-, generarse desde una confianza y legitimidad social y política lo más amplia posible de todas las autoridades del sistema democrático. Esa sólida credibilidad hoy no existe. Y segundo; actualmente, el parlamento requiere de una legitimidad de representatividad política que hoy no tiene, entre otras cosas, porque no debemos olvidar que la mitad del senado actual fue elegido con el sistema electoral binominal, esa mitad del senado cesa en su periodo recién el año 2021.

\section{A MODO DE SÍNTESIS: LA MOVILIZACIÓN POPULAR EN CHILE; RETORNO A LO POLÍTICO}

Entonces, a la pregunta; ¿qué ha sucedido con los chilenos y chilenas? Debemos responder que el modelo político chileno sustentado en un neoliberalismo extremo, exigía a las personas sacrificarse todo lo que pudieran a cambio de la promesa de terminar siendo ricos en las últimas etapas de sus vidas. Después de 30 años terminada la dictadura, las personas se dieron cuenta que solo algunos, unos muy pocos privilegiados recibían a manos llenas los beneficios del modelo, y esa minoría ha acumulado y sigue acumulando riquezas escandalosamente obscenas. En cambio, los de abajo, el pueblo, la inmensa mayoría de la población, comienza a hacer conciencia y certeza de que lo único que ha logrado acumular son deudas, sacrificios y más deudas, y que la tierra prometida de las riquezas, del buen pasar y de la prosperidad, era un espejismo definitivamente inalcanzable.

Los núcleos familiares a la vuelta de varios años se enorgullecían de que uno de sus hijos o hijas asistían por primera vez a la universidad, pero al pasar del tiempo, esos títulos y diplomas no le han sido útiles para llegar a la cúspide social como se lo prometieron, por el contrario, se 
dieron cuenta amargamente que en esta sociedad de clases -como la chilena- lo que verdaderamente importa no es el estudio sino el nombre, el apellido, las redes sociales y familiares, el "colegio" desde donde se proviene. Y lo peor de todo, es que esa juventud ingenuamente ilusionada terminó endeudada por 20 o más años para pagar los estudios realizados, y quedar hipotecados de por vida al haber adquirido una escala al éxito que terminaba siendo a la hora de la verdad, una vulgar estafa.

A los trabajadores y trabajadoras de los años ochenta les prometieron que jubilarían con su mismo sueldo y que no tendrían de qué preocuparse, las AFP eran una maravilla, un invento mágico, la fórmula perfecta. La gente forzadamente tuvo que creer y no tuvo otra alternativa, hoy día, las jubilaciones que perciben son una miseria que no les alcanza para vivir y ni siquiera para llegar a fin de mes digna y decentemente. Los jubilados pasan a ser carga de sus hijos, que, a su vez, están sobreendeudados por sus propios estudios y sus propios dramas familiares.

Los abusos sistemáticos y permanentes de las grandes empresas de servicios como salud, educación, productores de bienes de primera necesidad y distribuidores como supermercados (papel higiénico, pañales, medicamentos), trajeron consigo que las personas se dieran cuenta que el Estado en nada las protegía de los abusos groseros de los dueños del poder económico. Consorcios que se benefician del capital y que colocan en sus AFP en un tejido perverso de negocios que, además, crea universidades privadas y se compran canales de televisión y periódicos, como estrategia cultural global para dominar a las personas para que no perciban el abuso permanente del modelo neoliberal que les afecta y los usa. Así, dejamos de ser ciudadanos para sólo ser consumidores.

De la misma manera, las personas percibieron los abusos y la sobreexplotación laboral, todos y todas saben en la práctica cómo las empresas ganaban ocultando utilidades o la rentabilidad omnipotente que obtenían para no pagar y escamotear pequeñas gratificaciones, o que maquillaban sus resultados para que en las negociaciones colectivas en vez de ganar un poco más los trabajadores salieran para atrás nuevamente. No es casualidad que los empresarios siempre han querido no tener sindicatos e influir por medio del financiamiento a campañas políticas de parlamentarios y presidentes, con el objetivo claro de detener las presiones por 
legislación en pro del fortalecimiento de la sindicalización. De esta y muchas otras maneras, detener cualquier atisbo de redistribución de la riqueza.

En síntesis, las personas, el pueblo de Chile, tomó conciencia de que el modelo socio político y económico de carácter neoliberal los ha perjudicado grave y fatalmente en sus expectativas de avanzar socialmente por medio de la educación; en las proyecciones de su legítimo y necesario descanso después de haber entregado una vida al quehacer laboral; víctimas permanentes como consumidores sin protección ante el abuso de las grandes empresas; como trabajadores y trabajadoras que han sido humillados y explotados laboralmente durante los últimos 40 años.

Esto es lo que hoy el pueblo chileno, el ciudadano común tiene nítidamente claro en su conciencia y en su hablar. También lo tienen claro quiénes han sido los responsables, por un lado, los empresarios que han amplificado su riqueza a partir de estos abusos, y los políticos, primero los de derecha que fundaron el modelo $\mathrm{y}$, posteriormente, los socialdemócratas que lo administraron. Esta es la verdad que se ha cristalizado en la conciencia del pueblo chileno hoy y que claramente no parará de protestar hasta ver que todo cambie. Esto es retornar a lo político desde el pueblo, desde los desposeídos que están dejando definitivamente atrás la pesadilla del neoliberalismo en Chile.

Submetido em: 08/04/2020

Aprovado em: 29/04/2020 